\title{
How not to render an explanatory version of the evidential argument from evil immune to skeptical theism
}

\author{
Daniel Howard-Snyder
}

Received: 30 October 2014 / Accepted: 12 December 2014

(C) Springer Science+Business Media Dordrecht 2014

\begin{abstract}
Among the things that students of the problem of evil think about is whether explanatory versions of the evidential argument from evil are better than others, better than William Rowe's famous versions of the evidential argument, for example. Some of these students claim that the former are better than the latter in no small part because the former, unlike the latter, avoid the sorts of worries raised by so-called "skeptical theists". Indeed, Trent Dougherty claims to have constructed an explanatory version that is "fundamentally immune to considerations pertaining to skeptical theism". I argue that he has done no such thing.
\end{abstract}

\footnotetext{
1 See Rowe (1979, 1986, 1988, 1991, 1996, 2003).

2 For example, Draper (1992), Draper and Dougherty (2013), and Dougherty (2014).

${ }^{3}$ Howard-Snyder, unpublished.
} 
predictable on naturalism than theism, a fact about other explanatory versions that skeptical theists and their ilk have exploited. ${ }^{4}$ Indeed, not only does Dougherty's version have no such premise, it is "fundamentally immune to considerations pertaining to skeptical theism" —or so he says. Is he right?

Here's the relevant passage:

Given: The universe seems indifferent to the suffering of sentient beings.

1. It is known that the hypothesis of indifference predicts the data of an apparently indifferent universe.

2. It is unknown whether the hypothesis of theism predicts the data.

3. The hypotheses have approximately equal prior probabilities [that is, equal chance of being true before considering observational evidence].

4. Therefore, the data confirm the hypothesis of indifference and not the hypothesis of theism.

Here is how the argument works. Imagine a pair of scales in which we are weighing evidence concerning theism and atheism. One side of the scales is labeled "Theism" and the other side is labeled "Hypothesis of Indifference." Premise 3 says the scales are at first even. Premise 2 says that there is nothing to put on the scale marked "Theism." Premise 1 says that there is something to put on the scale marked "Hypothesis of Indifference." The conclusion says that after we have weighed the evidence, the scales tip to the side labeled "Hypothesis of Indifference."

Not only does this argument not make a noseeum inference, it doesn't assign any probability at all to observed evils given theism. So this version seems to be fundamentally immune to considerations pertaining to skeptical theism, except insofar as they can be brought to bear on premise $3 .^{5}$

What should we make of this argument and its informal commentary? I'll categorize my answer to this question under two headings: the data and the argument.

But first a remark about "the Hypothesis of Indifference" (HI). Dougherty never tells us what it is. Many of us, however, will recognize it from Draper's work, where it is used to refer to the hypothesis that "neither the nature nor the condition of sentient beings on earth is the result of benevolent or malevolent actions performed by nonhuman persons". 6 Presumably Dougherty has the same thing in mind.

\section{The data}

We are told that it is "given" that "The universe seems indifferent to the suffering of sentient beings." What does that mean? We can give this sentence a de re reading and a de dicto reading. On the de re reading, there is an $\mathrm{x}$ such that $\mathrm{x}$ is numerically identical with the universe and $x$ has the property of seeming indifferent to the suffering of sentient beings. On the de dicto reading, there is a proposition, the proposition

\footnotetext{
${ }^{4}$ See, e.g., Bergmann (2009) and Howard-Snyder, unpublished.

${ }^{5}$ Dougherty (2014, Sect. 6.3).

${ }^{6}$ Draper (1989, p. 13).
} 
that the universe is indifferent to the suffering of sentient beings, and that proposition has the property of seeming to be true. My purposes will be served on either reading since what I have to say can be said about both, mutatis mutandis. I choose the de dicto reading. Notice that, on the de dicto reading, we are told that what's "given" as our "data" is that (i) there is a certain proposition - the proposition that the universe is indifferent to the suffering of sentient beings—and (ii) that proposition has the property of seeming to be true. Call this conjunction the data proposition and call the proposition brought to our attention in the first conjunct the core proposition.

Now focus on the core proposition, the proposition that the universe is indifferent to the suffering of sentient beings. Notice two things about it. First, it presupposes that there is something that answers to "the universe" and, second, it attributes a mental state to it, the state of indifference. Some of us, impressed by the unsettled state of theorizing about the metaphysics of parts and wholes, might well wonder whether there is anything that answers to "the universe". But even those of us who have no such qualms will insist that it is unwise to ascribe a mental state to the universe. After all, the universe is an inanimate object and, as a matter of necessity, inanimate objects lack mental states. Taken strictly and literally, it's going to be a hard sell that the core proposition has the property of seeming to be true.

Diagnosis Dougherty is speaking metaphorically. He doesn't really mean to draw our attention to the proposition that there is a universe that has a certain mental state, the state of indifference. What he means to draw our attention to is a proposition that is much less contentious, e.g., that sentient beings on earth suffer in a variety of ways without need or benefit, or something like that. Although this is a significant improvement, in what follows I will use the proffered metaphorical expression of the core proposition.

So we have the core proposition and a claim about it: that it seems to be true, that it has the property of seeming to be true. Here we need to slow down. Do we really want to say that the core proposition has the property of seeming to be true? How could we tell such a thing? More importantly, what is that property, the property of seeming to be true, which the proponent of the argument—call her Athea—says that the core proposition has?

Here we would do well to remember that there's a world of difference between saying something of the form "p seems to me to be true" or "it seems to me that p" and saying something of the form " $p$ seems to be true" or "it seems that $p$ ". Whether any particular utterance by me of the former pair is true is a matter of how things stand with respect to $m e$, e.g., whether I am in a seeming state toward p when I consider it. Whether any particular utterance of the latter pair is true, however, is not a matter of how things stand with respect to me (or you, for that matter). Rather, it is more a matter of how things stand with respect to $p$ itself. We meet a peculiar resident at the local psychiatric ward who claims to be Cleopatra. No doubt it seems to her that she is Cleopatra, no doubt that proposition seems to be true to her. But should we infer that the proposition that she is Cleopatra, the proposition itself, thereby has the property of seeming to be true? Surely not. The same goes for Athea. The proposition that the universe is indifferent seems to her to be true. But it hardly follows that that proposition has the property of seeming to be true. If ever there was a fallacy, the 
overreaching seemer's fallacy is one: "p seems to me to be true, so $p$ seems to be true" or "it seems to me that $\mathrm{p}$, so it seems that $p$ ". So what is this property of $\mathrm{p}$, the property of its seeming that $p$, if it isn't the property of its seeming to me that $\mathrm{p}$ ?

Although simpliciter seemingness isn't the same property as to-me-seemingness, as we might call them, presumably the former is not completely unrelated to the seeming states of such persons as there may be. Suppose there were no persons, and so there was no one with respect to which any proposition seemed any way. In that case, would some proposition still seem to be true, would some proposition have the property of simpliciter seemingness? I suspect not. If that's right, then whether or not a proposition $\mathrm{p}$ has that property is not completely a matter of how things stand with respect to $\mathrm{p}$ itself, without reference to the seeming states of anyone.

Are there any propositions that paradigmatically count as having the property of simpliciter seemingness? Consider the proposition that $2+2=4$, or the proposition that everything red is colored, or the conditional corresponding to modus tollens. If any proposition has the property of simpliciter seemingness, the property of seeming to be true, these do. So then, suppose they do, and suppose their having simpliciter seemingness is a matter of their seeming true to some people or other.

But which people? That's a surprisingly difficult question to answer. In virtue of which people, and what proportion of them, is any particular proposition such that it - the proposition itself-has the property of seeming to be true, the property of simpliciter seemingness? Call this the "reference class problem".

Let's think very briefly about some solutions. They fall into two mutually exclusive and jointly exhaustive classes: (i) the property a proposition has when it seems simpliciter to be true is identical with or otherwise closely related to the property of its seeming to be true to everyone who considers it, and (ii) the property a proposition has when it seems simpliciter to be true is identical with or otherwise closely related to the property of its seeming to be true to some but not all people who consider it.

The problem with the everyone solution, as we might call it, is that it's false. Some people who consider at least some of our paradigms are just, well, screwed up. There's no nice way to put it. Either they don't understand them when they consider them or they understand them but they "just don't get it," as they say. More importantly for present purposes, even if our paradigms were such that they seemed to be true to everyone who considered them, that wouldn't help Athea. That's because it is false that the core proposition - the proposition that the universe is indifferent to the suffering of sentient beings - seems to be true to everyone who considers it. For example, it doesn't seem to be true to me when I consider it. And I'm not alone. It doesn't seem to be true to many people when they consider it, especially many students of the problem of evil. So on the everyone solution to the reference class problem, the data proposition is false.

What about the alternative, the some-but-not-all-people solution? The problem with it is that it is enormously difficult to say which people, and what proportion of them, count, and to say so in a way that does not smack of arbitrariness. We can see this especially in the case we are concerned with. Athea must specify just which people count, and which don't, and explain why her specification is correct. Of course, it would be arbitrary in the extreme for her to answer that the only people who count are those to whom the core proposition in fact seems to be true. So there must be some 
other way, some non-arbitrary way to identify a population whose seeming states are the relevant ones, relevant to the question of how we are to understand what, exactly, this property of simpliciter seemingness is supposed to be. Has anyone discovered such a way? Of course not. Any such population is a pipedream. But just to pursue the matter a little further, suppose we do find some non-arbitrary way to identify our pipedream population, and suppose we poll them for the seemers and the no-seemers. (Note well: the no-seemers need not be those to whom the core proposition seems false. I would think that, typically, the no-seemers will be those who lack a proseeming state when they consider the core proposition, which is not the same thing as its seeming to them that it's false.) Suppose the seemers achieve a simple majority—by one. Well then, on the principle that a simple majority wins, the core proposition-the proposition that the universe is indifferent to the suffering of sentient beings-has the property of simpliciter seemingness: it seems to be true. But now imagine that two of the seemers die in an auto accident. Then the no-seemers have a majority by one. Has the core proposition just lost the property of simpliciter seemingness? Or imagine that whenever the no-seemers discover that the seemers have a majority, they knock off just enough seemers to make the core proposition lose that property. Does the core proposition keep gaining and losing the property of simpliciter seemingness? Perhaps the simple majority principle isn't the right one. Perhaps there's another principle, for example the two-thirds majority principle. But why prefer it? For that matter, why prefer any of them? Doesn't it all seem just a little... arbitrary? More importantly, is this really the sort of reflection and concern that Dougherty wants us to bring to a consideration of the data of his explanatory version of the evidential argument from evil?

Of course, it might be that when Athea informs us that "The universe seems indifferent to the suffering of sentient beings" she means to say neither more nor less than that "The universe seems to me-Athea-to be indifferent to the suffering of sentient being". Suppose that's true. Then we have an explanatory version of the argument from evil for atheism that takes as its datum, as what's "given," that it seems to Athea that the universe is indifferent to the suffering of sentient beings, that the core propositionthat the universe is indifferent to the suffering of sentient beings- has the property of seeming to be true to Athea. While some people may find this datum to be compelling evidence to think that there is no God, I have a difficult time getting jazzed up about it.

Upshot Athea informs us that it is "given" that "The universe seems indifferent to the suffering of sentient beings". However, it's difficult to know what she's proposing as "given". It can't be that it seems that an inanimate object, the universe, has a mental state, the state of indifference. But when we turn to something less contentious, we're left with the overreaching seemer's fallacy or the reference class problem or something of relatively little interest. So what's the "data"? What's "given"?

Of course, if what's given is simply the core proposition-i.e., the proposition that the universe is indifferent to the suffering of sentient beings - and not the additional claim that that proposition seems to be true, then we won't have any difficulties of the sort I've just been surveying. But if we go this route, then it becomes very important to know what non-metaphorical proposition, exactly, is "given". If it is the proposition that sentient beings on earth suffer in a variety of ways without need or benefit, we might well wish to ask "Without need for what? And, without benefit for whom?" 
If the answer is "Without need for anyone's good, and without benefit to anyone," we might well then ask, "Why do you suppose that sentient beings on earth suffer in a variety of ways without need for anyone's good or benefit to anyone?" If the answer is "Because we can't think of any good for which it is needed and we can't think of any benefit for anyone," then we will not have been given an argument that is "fundamentally immune to considerations pertaining to skeptical theism".

I propose to pretend in what follows that we know what data is given. Now let's inspect the argument itself, with Dougherty's claim in mind: that the argument he states is "fundamentally immune to considerations pertaining to skeptical theism". (The qualification "except insofar as they can be brought to bear on premise 3" need not concern us.)

\section{The argument}

There are three points to make about Dougherty's argument in relation to his claim.

First, (4) does not follow from premises (1) to (3). According to Athea, the data confirm HI but not theism since, given equal priors, it is known that HI predicts the data and it is unknown whether theism predicts it. That's a non-sequitur. At best, all that follows is

4'. The data confirm HI and it is unknown whether the data confirm theism.

Notably, at least some of those who are attuned to "considerations pertaining to skeptical theism" will warmly embrace ( $\left.4^{\prime}\right)$. Indeed, this is exactly the sort of thing the skeptical theist might say, not to mention her friends the skeptical atheist and the skeptical agnostic.

In order to avoid the non-sequitur and the warmly embracable (4'), we must add a premise to Dougherty's argument. Perhaps this will do: it is known that theism does not predict the data. Or perhaps this: theism does not predict the data. I'm not sure which to add, but add we must lest our interest in Dougherty's argument turns to dust.

Let's mention both of them and leave it up to Athea which she would prefer:

2.5 (It is known that) theism does not predict the data.

Second, in the first paragraph of the informal commentary Dougherty uses the scale metaphor to tell us "how the argument works". There we read this sentence: "Premise 2 says that there is nothing to put on the scale marked "Theism." This sentence is false. That's because premise (2) in the argument states " 2 . It is unknown whether the hypothesis of theism predicts the data" and, if we aim to translate (2) into the terms of the scale metaphor, we should say "Premise (2) says that it is unknown whether there is anything to put on the scale marked 'Theism'," and not what Dougherty says. Of course, when we dwell a moment on this better translation of premise (2), we will want to ask "Unknown to whom?," the answer to which can only be "us," in which case the best translation of (2) in the terms of the scale metaphor is "It is unknown to us whether there is anything to put on the scale marked 'Theism"'. Now, I submit that it's pretty close to obvious that the way to translate premise (2) of Dougherty's argument is not "There is nothing to put on the scale marked 'Theism"' but rather "It is unknown to us whether there is anything to put on the scale marked 'Theism"'. How could 
someone confuse the former for the latter? Well, if one were unconsciously drawing the inference "It is unknown to us whether there is anything to put on the scale marked 'Theism'; therefore, there is nothing to put on the scale marked 'Theism'," one might engage in that confusion. Indeed, it's difficult not to see in the informal commentary an implicit noseeum inference like this. And, as everyone knows, noseeum inferenceswhether explicit or implicit—are hardly "fundamentally immune to considerations pertaining to skeptical theism".

Third, if there is a noseeum inference implicit in Dougherty's informal commentary, we might well expect to find one implicit in the argument itself, or something close enough to one so as not to be "fundamentally immune to considerations pertaining to skeptical theism". Is our expectation well-founded? Well, the argument explicitly contains this premise:

2. It is unknown [to us] whether the hypothesis of theism predicts the data.

And, as we've seen, the argument is a non-sequitur unless we charitably add premise (2.5):

\section{5 (It is known that) the hypothesis of theism does not predict the data.}

Once we exercise charity, however, we might well ask how these two premises are related to each other. Do they just show up in the argument side-by-side, having nothing to do with each other? Surely not. Surely the thrust of thought here requires a closer connection than that. Surely it requires that the latter is inferred from the former. Thus, a more perspicuous expression of Dougherty's explanatory version of the evidential argument from evil goes as follows:

1. It is known that $\mathrm{HI}$ predicts the data of an apparently indifferent universe.

2. It is unknown [to us] whether theism predicts the data.

\subsection{Therefore, (it is known that) theism does not predict the data. (2.5)}

3 . The hypotheses have approximately equal prior probabilities.

4. Therefore, the data confirm $\mathrm{HI}$ and not theism. $(1,2.5,3)$

And, clearly enough, the inference from (2) to (2.5) is not "fundamentally immune to considerations pertaining to skeptical theism".

After all, one might well wonder on the basis of considerations pertaining to skeptical theism whether, grounds for belief in God aside, it would be unknown to us whether theism predicts the data or exactly how it predicts the data, if it did predict it. Moreover, one might well wonder on the basis of considerations pertaining to skeptical theism whether (i) the move from "Theism has the property of being unknown by us to predict the data" to "Theism has the property of not predicting the data" is reasonable, or whether (ii) the move from "Theism has the property of being unknown by us to predict the data" to "Theism has the property of being known by us not to predict the data" is reasonable. Furthermore, one might well point out that theism does not predict that the universe seems indifferent to the suffering of sentient beings only if there is no good or other reason that would justify God in permitting the universe to seem indifferent to the suffering of sentient beings—an obvious implication that we must not be in doubt about if we are to reasonably infer that theism does not predict the data. In that case, one might naturally wonder why we should believe that there is 
no such good or other reason. The fact that the argument or its informal commentary already invites us to move easily from the unknown to the known strongly suggests that lurking here is another such invitation, to move easily from "we don't know of any such good or other reason" to "there is no such good or reason"-which is hardly "fundamentally immune to considerations pertaining to skeptical theism".

It may well be that one day someone will come up with an explanatory version of the evidential argument from evil that is "fundamentally immune to considerations pertaining to skeptical theism". This much is clear, however: if Dougherty's argument is any indication of the prospects for such an argument, that day is a long way off. ${ }^{7}$

\section{References}

Bergmann, M. (2009). Skeptical theism and the problem of evil. In T. Flint \& M. Rea (Eds.), Oxford handbook of philosophical theology (pp. 375-399). Oxford: Oxford University Press.

Dougherty, T. (2014). Skeptical theism. In E. N. Zalta (Ed.), The stanford encyclopedia of philosophy. http:// plato.stanford.edu/archives/spr2014/entries/skeptical-theism/.

Draper, P. (1989). Pain and pleasure: An evidential problem for theists. Nous, 23, 331-350.

Draper, P. (1992). Probabilistic arguments from evil. Religious Studies, 28, 303-317.

Draper, P., \& Dougherty, T. (2013). Explanation and the problem of evil. In J. McBrayer \& D. HowardSnyder (Eds.), The Blackwell companion to the problem of evil (pp. 67-82). Walden, MA: Wiley Blackwell.

Howard-Snyder, D. (Unpublished). "Agnosticism and draper's explanatory version of the evidential argument from evil".

Rowe, W. (1979). The problem of evil and some varieties of atheism. American Philosophical Quarterly, $16,335-341$.

Rowe, W. (1986). The empirical argument from evil. In R. Audi \& W. Wainwright (Eds.), Rationality, religious belief and moral commitment (pp. 227-247). Ithaca, NY: Cornell University Press.

Rowe, W. (1988). Evil and theodicy. Philosophical Topics, 16, 119-132.

Rowe, W. (1991). Ruminations about evil. Philosophical Perspectives, 5, 69-88.

Rowe, W. (1996). The evidential argument from evil: A second Look. In D. Howard-Snyder (Ed.), The evidential argument from evil (pp. 262-285). Bloomington, IN: Indiana University Press.

Rowe, W. (2003). Grounds for belief aside, does evil make atheism more reasonable than theism? In M. Peterson \& R. J. VanArragon (Eds.), Contemporary debates in philosophy of religion (pp. 3-12). Malden: Blackwell.

\footnotetext{
7 Thanks to Hud Hudson and Justin McBrayer for comments on earlier drafts of this paper.
} 